\title{
The Quality of Randomized Clinical Trials in the Field of Surgery: Studies on Laparoscopic versus Open Appendectomy as an Example
}

\author{
O. Sadr-Azodi ${ }^{a} b \quad$ A. Andrén-Sandberg ${ }^{b}$ \\ a Department of Medicine, Unit of Clinical Epidemiology, Karolinska Institutet, and ${ }^{\mathrm{b}}$ Department of Surgery, \\ Karolinska University Hospital, Huddinge, Stockholm, Sweden
}

\section{Key Words}

Laparoscopic appendectomy • Open appendectomy • CONSORT

\begin{abstract}
Background: The field of surgery undergoes rapid renewal and introduction of surgical techniques and instruments. Thus, the quality of the randomized clinical trials in this field should be evaluated. We assessed the quality of randomized trials comparing laparoscopic versus open appendectomy as a model. Method: Using MEDLINE and EMBASE, 42 firsttime published randomized clinical trials in the English language met the inclusion criteria. Factors related to the methodological quality, e.g. blinding, sample size calculation and intention-to-treat analysis, were reviewed. Results: Method of random number generation was described in only 15 (36\%) of the studies, i.e., it was not clear if the remaining two thirds of the studies were actually randomized or not. Although not using blocking, the trials often reported similar sample size in the intervention and control groups. Proper concealment of the allocation status was reported in almost half of the studies. None of the trials was judged to use proper double-blinding measures. Sample size calculation was present in one of five trials and half of the studies performed analysis according to intention-to-treat. Conclusions: It seems that surgical trials do not always follow the basic methodological guidelines to maintain the high quality of
\end{abstract}

randomized clinical trials. Compliance with the CONSORT statement and transparency in result reporting is strongly recommended to improve the quality of randomized trials in the field of surgery.

Copyright $\odot 2009$ S. Karger AG, Basel

\section{Introduction}

Randomized clinical trials (RCTs) are the gold standard in evidence-based medicine. To maintain the high quality, there are several guidelines that must be followed [1]. The field of surgery undergoes rapid introduction and renewal of surgical techniques and instruments. Thus, it is important that the efficacy and safety of these techniques and instruments are properly evaluated. Acute appendicitis is a common indication of abdominal surgery with a life-time incidence between 7 and 9\% [2]. In the early 1980s, Semm [3] introduced a laparoscopic technique for appendectomy and since then, this approach has gained popularity at the expense of open appendectomy. The possible benefits of laparoscopic appendectomy over open appendectomy have been studied in numerous RCTs.

We used this area of research as a model to review the quality of RCTs in the field of surgery and to discuss how the study design should be improved to ensure the high standard of randomized controlled trials.

\section{KARGER}

Fax +4161306 1234 E-Mail karger@karger.ch www.karger.com

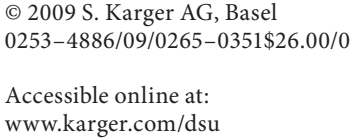

Omid Sadr-Azodi

Clinical Epidemiology Unit T2

SE-171 76 Stockholm (Sweden)

Tel. +46858580 000, Fax +46831 1101

E-Mail sayed-omid.sadrazodi@ki.se 


\section{Methods}

\section{Inclusion Criteria}

RCTs that compared laparoscopic and open appendectomy between 1983 (first report on laparoscopic appendectomy [3]) and September 2008, irrespective of the study outcome, were included in this paper. Only the first-time published original articles in the English language were considered eligible.

\section{Sources of Data}

Using MEDLINE and EMBASE, a literature search was carried out to identify relevant papers. Search terms used were [open] $+\left[\right.$ laparosc $\left.^{*}\right]+[$ appendectomy $]+\left[\right.$ random*$\left.^{*}\right]$.

\section{Identification of Relevant Papers}

On the 25th of September 2008, 110 citations were available, 49 of which were RCTs comparing open and laparoscopic appendectomy. Of these, 7 were omitted ( 3 were not accessible through the internet network of the university library of Karolinska Institutet and no contact information was available to contact the first authors in order to receive reprints of the papers [4-6]; four other studies used the material of an already published RCT [7-10]). As a result, 42 [11-52] papers remained for inclusion in this study.

\section{Data Extraction}

Trial characteristics and factors related to the trial quality, namely randomization procedure (method of random number generation, blocking, concealment, blinding), sample size calculation and intention-to-treat (ITT) analysis, were extracted. Jadad score [53] was used to evaluate the overall quality of the included papers.

\section{Results}

\section{Baseline Characteristics}

Baseline characteristics of the included trials are shown in table 1 . Almost half of the studies were conducted after the year $2000(\mathrm{n}=19,45 \%)$. Europe was the most frequent study setting $(\mathrm{n}=23,55 \%)$. The median sample size was 90 (11-583). Four studies included only males $[11,12,18,44]$, four included premenopausal women only $[19,21,26,39]$ and five included exclusively children $[17,22,24,25,43]$. No trial reported registration of the trial protocol.

\section{Randomization Procedure}

Different parameters related to the quality of the trials are summarized in table 2 . The method of random number generation was clearly described in 15 (36\%) of the RCTs. Of these, 7 (46\%) used computer-generated randomization, 4 (26\%) random number tables, $1(7 \%)$ 'a master list with 10 repeating random numbers sequence', $1(7 \%)$ coin toss, $1(7 \%)$ admission code and $1(7 \%)$ instrumental availability as the method of random number generation. The remaining 27 (64\%) did not mention the method of random number generation.

Six (14\%) studies used blocking, all of which stated the size of the block (ranging from 4 to 52). In one study the size of the block alternated between 4 and 12 . The study with a block size of 52 used one single block only. One (2\%) study reported the use of stratified randomization based on age and gender in combination with blocking. Although not specifying the type of randomization, the remaining $36(86 \%)$ most likely used simple randomization. The median difference between the sample size in the intervention and control group was $6 \%(0-167 \%)$. The study with a sample size difference of $167 \%$ had a predefined almost 2:1 randomization ratio. Five other studies only presented the number of participants in each group after post-entry exclusion of individuals from the study. However, the median difference in sample size did not change substantially when excluding these six trials $(5 \%(0-47 \%))$. The difference between the size of the intervention and control group in studies using blocking was $4 \%(0-13 \%)$. For studies with simple randomization excluding the trial with the $2: 1$ ratio, this figure was $8 \%$ $(0-47 \%)$.

In 18 (43\%) trials, there was no information about the presence of measures to conceal the allocation before randomization. Twenty studies (48\%) provided this information. One (5\%) study used central randomization, another (5\%) used sealed, opaque, numbered envelopes, 2 (10\%) had sealed, opaque envelopes without information about numbering of the envelopes, $12(60 \%)$ reported sealed envelopes, 1 (5\%) opaque envelopes, $2(10 \%)$ stated 'envelopes' only and finally, 1 (5\%) study used 'sealed assignment cards'. The remaining four (9\%) trials did not have any allocation concealment (the allocation was based on coin toss, availability of the instruments for laparoscopic appendectomy, admission codes of the patients and which surgeon attending the call).

Seven (17\%) RCTs reported blinding. Three used a wound dressing that covered the whole abdomen, 3 used wound dressings to resemble the incisional wounds after laparoscopic and open appendectomy, and 1 study reported the use of identical wound dressings, but did not specify if these were covering the entire abdomen or resembled the incisional wounds. The 3 first studies claimed to be double-blinded.

\section{Statistical Analysis}

Sample size calculation was performed in 9 (21\%) studies and in all of them, the estimated number of participants was reached. The analyses were performed ac- 
Table 1. Baseline characteristics of the included studies

\begin{tabular}{|c|c|c|c|c|c|c|}
\hline \multirow[t]{2}{*}{ Author } & \multirow{2}{*}{$\begin{array}{l}\text { Publication } \\
\text { year }\end{array}$} & \multirow{2}{*}{$\begin{array}{l}\text { Study } \\
\text { setting }\end{array}$} & \multirow{2}{*}{$\begin{array}{l}\text { Number } \\
\text { of patients }\end{array}$} & \multicolumn{2}{|l|}{ Age } & \multirow[t]{2}{*}{ Participants } \\
\hline & & & & $\mathrm{O}$ & $\mathrm{L}$ & \\
\hline Ricca [11] & 2007 & USA & 52 & $31^{\mathrm{a}}$ & & overweight men \\
\hline Tzovaras [12] & 2007 & Greece & $78^{\mathrm{b}}$ & $22(14-65)$ & $26(15-68)$ & men \\
\hline $\begin{array}{l}\text { Katkhouda } \\
{[13]}\end{array}$ & 2005 & USA & 268 & $28(17-63)$ & $29(18-71)$ & $>15$ years \\
\hline Olmi [14] & 2005 & Italy & 252 & $23(5-80)$ & $25(6-86)$ & all ages \\
\hline Almagor [15] & 2005 & Israel & 37 & $28 \pm 13$ & $35 \pm 16$ & histologically confirmed diagnosis of AA \\
\hline Moberg [16] & 2005 & Sweden & 219 & $31(15-83)$ & $31(15-71)$ & $>15$ years, randomized after laparoscopy \\
\hline Oka [17] & 2004 & USA & 517 & $11(2-17)$ & $11(2-20)$ & children \\
\hline Ignacio [18] & 2004 & USA & 52 & $27 \pm 9$ & $28 \pm 7$ & men \\
\hline van Dalen [19] & 2003 & New Zealand & 63 & $22(16-51)$ & $24(16-45)$ & premenopausal women \\
\hline Milewczyk [20] & ]2003 & Poland & 200 & $28^{\mathrm{b}}$ & 26 & both gender \\
\hline $\begin{array}{l}\text { Al-Mulhim } \\
{[21]}\end{array}$ & 2002 & Saudi Arabia & 60 & $26(14-42)$ & $23(14-35)$ & premenopausal women \\
\hline Little [22] & 2002 & USA & 129 & $10(1-15)$ & $12(1-16)$ & children \\
\hline Huang $^{\mathrm{c}}[23]$ & 2001 & Taiwan & 75 & $34 \pm 12$ & $32 \pm 25$ & $>12$ years \\
\hline Lavonius [24] & 2001 & Finland & 43 & $12(8-15)$ & $12(7-15)$ & children \\
\hline Lintula [25] & 2001 & Finland & 73 & $12 \pm 3$ & $11 \pm 3$ & children \\
\hline Larsson [26] & 2001 & Sweden & 110 & $25 \pm 8$ & $25 \pm 8$ & premenopausal women \\
\hline Long [27] & 2001 & USA & 200 & not stated & & $>15$ years \\
\hline Pedersen [28] & 2001 & Denmark & 583 & $27(18-40)^{\mathrm{d}}$ & $26(18-40)$ & all ages \\
\hline $\begin{array}{l}\text { Nordentoft } \\
\text { [29] }\end{array}$ & 2000 & Denmark & 30 & not stated & & $>18$ years \\
\hline Özmen [30] & 1999 & Turkey & 70 & $28(15-65)$ & $23(15-56)$ & all with suspected AA \\
\hline Perner [31] & 1999 & Denmark & 11 & $33(18-53)^{\mathrm{e}}$ & & not specified \\
\hline Hellberg [32] & 1999 & Sweden & 523 & not stated & & $>15$ years \\
\hline Heikkinen [33] & 1998 & Finland & 40 & $37(15-59)$ & $34(15-72)$ & $>14$ years \\
\hline Klingler [34] & 1998 & Austria & 169 & $24^{\mathrm{a}}$ & 30 & $>14$ years, $<70$ years \\
\hline Macarulla [35] & 1997 & Spain & 210 & $29 \pm 15$ & $27 \pm 13$ & $>12$ years \\
\hline Minne [36] & 1997 & USA & 57 & $31(14-55)^{\mathrm{d}}$ & $31(12-69)$ & $\geq 12$ years \\
\hline Reiertsen [37] & 1997 & Norway & 108 & $33(18-59)$ & $34(18-56)$ & $18-60$ years \\
\hline Kazemier [38] & 1997 & Netherland & 201 & $34 \pm 18$ & $31 \pm 14$ & $>11$ years \\
\hline Laine [39] & 1997 & Finland & 50 & $28(16-40)$ & $27(18-35)$ & premenopausal women \\
\hline Hart [40] & 1996 & Canada & 81 & $33 \pm 17$ & $29 \pm 12$ & suspected AA \\
\hline Mutter [41] & 1996 & France & 100 & $27(15-62)$ & $29(15-65)$ & $\geq 15$ years \\
\hline Williams [42] & 1996 & USA & 37 & $26(10-45)$ & $28(14-43)$ & not specified \\
\hline Lejus [43] & 1996 & France & 63 & $11 \pm 2$ & $11 \pm 2$ & children \\
\hline Cox [44] & 1996 & Australia & 64 & $25(18-84)$ & $25(18-75)$ & males $\geq 18$ years \\
\hline Hansen [45] & 1996 & Australia & 158 & $22(13-66)$ & $25(14-89)$ & $>12$ years \\
\hline Martin [46] & 1995 & USA & 169 & $29^{\mathrm{a}}$ & 27 & $>14$ years \\
\hline Ortega [47] & 1995 & USA & 253 & $25^{\mathrm{a}}$ & 26 & only adults \\
\hline $\begin{array}{l}\text { Lujan } \\
\text { Mompean [48] }\end{array}$ & 1994 & Spain & 200 & $26(7-70)$ & $30(7-84)$ & no exclusions \\
\hline Frazee [49] & 1994 & USA & 75 & $30(10-68)$ & $28(10-70)$ & $>9$ years \\
\hline Kum [50] & 1993 & Singapore & 137 & $31 \pm 7$ & $33 \pm 5$ & $>12$ years \\
\hline Tate [51] & 1993 & Hong Kong & 140 & $33(29-37)$ & $31(28-35)$ & suspected AA \\
\hline Attwood [52] & 1992 & Ireland & 62 & $27(15-67)$ & $21(12-39)$ & suspected AA \\
\hline
\end{tabular}

${ }^{\text {a }}$ Distribution unclear; ${ }^{\mathrm{b}}$ only males $(\mathrm{n}=78)$ randomized, females treated with laparoscopy only; ${ }^{\mathrm{c}}$ including a third arm with needlescopic appendectomy; ${ }^{\mathrm{d}}$ median and interquartile range; ${ }^{\mathrm{e}}$ total number of complications. $\mathrm{O}=\mathrm{Open}$ appendectomy; $\mathrm{L}=$ laparoscopic appendectomy. 
Table 2. Qualitative measures reported in RCTs comparing laparoscopic and open appendectomy

\begin{tabular}{|c|c|c|c|c|c|c|}
\hline Author & $\begin{array}{l}\text { Method for random } \\
\text { number generation }\end{array}$ & Blocking & Concealment & Blinding & ITT & Power analysis \\
\hline Ricca [11] & unclear & unclear & unclear & measures taken & unclear & performed, number reached \\
\hline Tzovaras [12] & unclear & unclear & unclear & unclear & yes & not stated \\
\hline $\begin{array}{l}\text { Katkhouda } \\
{[13]}\end{array}$ & computer-generated & unclear & appropriate & measures taken & no & performed, number reached \\
\hline Olmi [14] & admission code of the patients & unclear & inappropriate & unclear & unclear & not stated \\
\hline Almagor [15] & unclear & unclear & unclear & unclear & yes & not stated \\
\hline Moberg [16] & computer-generated & blocking & appropriate & measures taken & yes & performed, number reached \\
\hline Oka [17] & surgeon attending the call & unclear & inappropriate & unclear & yes & performed, number reached \\
\hline Ignacio [18] & unclear & blocking & unclear & measures taken & unclear & performed, number reached \\
\hline $\begin{array}{l}\text { van Dalen } \\
{[19]}\end{array}$ & unclear & unclear & appropriate & unclear & yes & not stated \\
\hline $\begin{array}{l}\text { Milewczyk } \\
{[20]}\end{array}$ & random number tables & unclear & unclear & unclear & yes & not stated \\
\hline $\begin{array}{l}\text { Al-Mulhim } \\
{[21]}\end{array}$ & unclear & unclear & appropriate & unclear & unclear & not stated \\
\hline Little [22] & unclear & unclear & appropriate & unclear & unclear & not stated \\
\hline Huang [23] & unclear & unclear & unclear & unclear & no & not stated \\
\hline Lavonius [24] & unclear & unclear & appropriate & unclear & unclear & not stated \\
\hline Lintula [25] & unclear & unclear & appropriate & measures taken & yes & not stated \\
\hline Larsson [26] & unclear & blocking & appropriate & unclear & no & not stated \\
\hline Long [27] & random number tables & blocking & appropriate & unlcear & yes & performed, number reached \\
\hline Pedersen [28] & computer-generated & unclear & appropriate & unclear & no & performed, number reached \\
\hline $\begin{array}{l}\text { Nordentoft } \\
{[29]}\end{array}$ & unclear & unclear & unclear & unclear & no & not stated \\
\hline Özmen [30] & unclear & unclear & unclear & unclear & yes & not stated \\
\hline Perner [31] & random number tables & unclear & appropriate & unclear & yes & not stated \\
\hline Hellberg [32] & computer-generated & blocking & appropriate & unclear & no & performed, number reached \\
\hline $\begin{array}{l}\text { Heikkinen } \\
{[33]}\end{array}$ & unclear & unclear & appropriate & unclear & no & not stated \\
\hline Klingler [34] & unclear & unclear & unclear & unclear & no & not stated \\
\hline $\begin{array}{l}\text { Macarulla } \\
{[35]}\end{array}$ & unclear & unclear & appropriate & unclear & no & not stated \\
\hline Minne [36] & $\begin{array}{l}10 \text { repeating random } \\
\text { numbers on a master list }\end{array}$ & unclear & unclear & unclear & no & not stated \\
\hline Reiertsen [37] & unclear & blocking & unclear & unclear & yes & performed, number reached \\
\hline Kazemier [38] & unclear & unclear & appropriate & unclear & yes & not stated \\
\hline Laine [39] & unclear & unclear & unclear & unclear & unclear & not stated \\
\hline Hart [40] & computer-generated & unclear & appropriate & unclear & no & not stated \\
\hline Mutter [41] & unclear & unclear & unclear & unclear & yes & not stated \\
\hline Williams [42] & unclear & unclear & unclear & unclear & unclear & not stated \\
\hline Lejus [43] & unclear & unclear & unclear & measures taken & yes & not stated \\
\hline Cox [44] & unclear & unclear & unclear & unclear & yes & not stated \\
\hline Hansen [45] & random number tables & unclear & appropriate & unclear & no & not stated \\
\hline Ortega [47] & unclear & unclear & inappropriate & measures taken & yes & not stated \\
\hline $\begin{array}{l}\text { Lujan } \\
\text { Mompean } \\
\text { [48] }\end{array}$ & instrumental availability & unclear & inappropriate & unclear & yes & not stated \\
\hline Frazee [49] & unclear & unclear & unclear & unclear & yes & not stated \\
\hline Kum [50] & coin toss & unclear & inappropriate & unclear & no & not stated \\
\hline Tate [51] & unclear & unclear & appropriate & unclear & yes & not stated \\
\hline Attwood [52] & unclear & unclear & appropriate & unclear & yes & not stated \\
\hline
\end{tabular}


cording to ITT in $21(50 \%)$ of the trials. In $10(48 \%)$, the use of ITT analysis was specified in the statistical analysis or results section, and in 11 (52\%), this information was retrieved by our review of the tables of results. The remaining 21 trials either did not perform ITT analysis $(\mathrm{n}=13,31 \%)$, or it was unclear whether such analysis was performed or not $(\mathrm{n}=8,19 \%)$.

\section{Jadad Score}

The overall quality of the RCTs was estimated by Jadad score. The score is between 0 and 5 with a higher score indicating higher quality. The median Jadad score of the included papers was $2(0-3)$. Four studies $(10 \%)$ had a score of $0,16(38 \%)$ scored $1,15(36 \%)$ scored 2 and $7(16 \%)$ had a Jadad score of 3 . None of the studies was considered to have appropriate measures of double-blinding ( 2 possible points).

\section{Discussion}

Overall, RCTs that compared laparoscopic and open appendectomy had low quality. A similar conclusion has been presented previously in a Cochrane meta-analysis by Sauerland et al. [54]. Unfortunately, we do not believe that the quality of surgical RCTs studying other treatments or diseases is so much different [55]. In order to improve the quality of randomized controlled trials in the field of surgery, there are some guidelines that should be followed.

Randomization reduces bias in treatment allocation, i.e., participants' baseline characteristics should not affect which treatment they will receive, and helps to balance the allocation groups for known and unknown prognostically important factors [1]. In this review, description of methods of random number generation was missing in almost two thirds of the trials. Although a minority, four $(10 \%)$ of the trials reported the use of systematic methods, such as the admission code of the patients or coin toss, to decide the allocation. Such methods are not random and are sources of bias [56].

When the sample size is small, simple randomization is not likely to result in treatment groups with equal size [1]. For instance, when 100 individuals are set to be randomized, the likelihood of having treatment groups with equal size using simple randomization is only $8 \%$ [1]. In the present review, the difference in sample size in unblocked RCTs was less than $10 \%$ and not different from those using blocking. This issue has also been reported by Altman and Doré [57]. In that study, 3 possibilities for this finding was discussed, namely: (1) use of blocking without reporting it, (2) use of nonrandom methods for randomization, and (3) adding extra patients to one treatment arm to balance the groups. The second and third possibilities are associated with selection bias.

Proper concealment helps investigators to be unaware of the allocation sequence and reduces the bias in selection of the study participants [58]. Inadequately concealed trials have been shown to overestimate the effect of size by up to $40 \%$ [59]. More than half of the RCTs in this review either had inadequate measures of concealment or did not provide any information about the way the concealment was arranged.

Blinding of the allocation status is an acknowledged difficulty in surgical trials [60]. The results from unblinded RCTs have been shown to differ from those of RCTs with blinded outcome assessment [61]. In the surgical field, the most efficient way to double-blind the outcome assessment is the use of sham surgery. However, the ethical concerns of using sham surgery is worth being debated [62,63]. In case of acute conditions such as acute appendicitis, the use of a sham procedure is not an option. In this review, 3 (7\%) of 42 studies using an abdominal dressing to cover the entire abdomen reported being double-blinded. However, we find it difficult to believe that this measure was enough to provide sustainable double-blinding throughout the whole follow-up period. Some factors that may reveal the allocated intervention could be: (1) wound dressings are easily accessible to patients and could be removed, (2) a wound will always have some discharge which could locate the actual wound site and concomitantly unmask the surgical procedure, and (3) pain from the wound site could reveal the type of surgery. In case of RCTs comparing different surgical approaches, incisions to create identical postoperative wounds may be a possible solution. Of course, these wounds do not have to be as deep as wounds associated with a given surgical procedure.

Sample size must be calculated before a study is conducted to quantitatively estimate the precision of a randomized trial to study a given hypothesis $[1,64]$. It could be argued that underpowered RCTs are unethical [65]. One strong argument is that by conducting a study with low statistical power, investigators will consume the trust of the study participants who have accepted the risks by being included in a trial [65]. Although meta-analyses may be a tool to pool the knowledge in a research field and improve the evaluation of the results, it must be kept in mind that underpowered studies are prone to bias [64]. Thus, the validity of meta-analyses' results could be com- 
promised when pooling estimates of underpowered trials [64]. Furthermore, underpowered studies are prone to publication bias [64]. The absence of information about these studies also deteriorates the validity of a meta-analysis [64]. Thus, it is the responsibility of the investigators to make sure that a planned study has sufficient precision and statistical power to test a given hypothesis.

When analyzing the results of a randomized trial, investigators may be tempted to exclude some particular individuals, such as those erroneously included in a trial or those not adhering to the randomized allocation, from the final analysis. Exclusion of those wrongly randomized to an RCT could be excusable if such exclusion is not different with respect to the allocation status [66]. However, exclusion on other bases, such as non-adherence to the allocated treatment, could be substantially prone to bias $[1,66]$. Thus, we recommend the use of ITT analysis as the primary way of describing the results of a randomized controlled trial. Any analysis after post-randomization exclusion of participants should be defined as secondary, and the reason for exclusion must be thoroughly reasoned.

\section{Conclusions}

The quality of studies in the field of surgery needs to be improved. A tool to systematize trial planning and reporting is the CONSORT statement [67]. Moreover, registration of the trial protocol is another way that improves transparency in result reporting [68]. We believe that adherence to the recommendations in conducting RCTs and the two tools mentioned above will substantially improve the quality of RCTs in the field of surgery.

\section{References}

1 Piantadosi S: Clinical Trials: A Methodologic Perspective. New York, Wiley-Interscience, 1997, p 121.

2 Addiss DG, Shaffer N, Fowler BS, Tauxe RV: The epidemiology of appendicitis and appendectomy in the United States. Am J Epidemiol 1990;132:910-925.

3 Semm K: Endoscopic appendectomy. Endoscopy 1983;15:59-64.

4 Moirangthem GS, Arunkumar C, Marak AB, Lokendra K, Singh LD: A comparative study between laparoscopic versus open appendectomy. JMS J Med Soc 2008;22:58-62.

5 Helmy MA: A comparative study between laparoscopic versus open appendicectomy in men. J Egypt Soc Parasitol 2001;31:555-562.

6 6 Bruwer F, Coetzer M, Warren BL: Laparoscopic versus open surgical exploration in premenopausal women with suspected acute appendicitis. S Afr J Surg 2003;41:82-85.

7 Kald A, Kullman E, Anderberg B, et al: Costminimisation analysis of laparoscopic and open appendicectomy. Eur J Surg 1999;165: 579-582.

8 Enochsson L, Hellberg A, Rudberg C, et al: Laparoscopic vs. open appendectomy in overweight patients. Surg Endosc 2001;15: 387-392.

9 Hellberg A, Rudberg C, Enochsson L, et al: Conversion from laparoscopic to open appendicectomy: a possible drawback of the laparoscopic technique? Eur J Surg 2001;167: 209-213.

10 Lintula H, Kokki H, Vanamo K, Antila P, Eskelinen M: Laparoscopy in children with complicated appendicitis. J Pediatr Surg 2002;37:1317-1320.
11 Ricca R, Schneider JJ, Brar H, Lucha PA: Laparoscopic appendectomy in patients with a body mass index of 25 or greater: results of a double blind, prospective, randomized trial. JSLS 2007;11:54-58.

12 Tzovaras G, Liakou P, Baloyiannis I, et al: Laparoscopic appendectomy: differences between male and female patients with suspected acute appendicitis. World J Surg 2007; 31:409-413

13 Katkhouda N, Mason RJ, Towfigh S, Gevorgyan A, Essani R: Laparoscopic versus open appendectomy: a prospective randomized double-blind study. Ann Surg 2005;242: 439-448; discussion 448-450.

14 Olmi S, Magnone S, Bertolini A, Croce E: Laparoscopic versus open appendectomy in acute appendicitis: a randomized prospective study. Surg Endosc 2005;19:1193-1195.

15 Almagor M, Mintz A, Sibirsky O, Durst A: Preoperative and postoperative levels of interleukin- 6 in patients with acute appendicitis: comparison between open and laparoscopic appendectomy. Surg Endosc 2005; 19: 331-333.

16 Moberg AC, Berndsen F, Palmquist I, Petersson U, Resch T, Montgomery A: Randomized clinical trial of laparoscopic versus open appendicectomy for confirmed appendicitis. Br J Surg 2005;92:298-304.

17 Oka T, Kurkchubasche AG, Bussey JG, Wesselhoeft CW Jr, Tracy TF Jr, Luks FI: Open and laparoscopic appendectomy are equally safe and acceptable in children. Surg Endosc 2004;18:242-245.
18 Ignacio RC, Burke R, Spencer D, Bissell C, Dorsainvil C, Lucha PA: Laparoscopic versus open appendectomy: what is the real difference? Results of a prospective randomized double-blinded trial. Surg Endosc 2004;18: 334-337.

19 van Dalen R, Bagshaw PF, Dobbs BR, Robertson GM, Lynch AC, Frizelle FA: The utility of laparoscopy in the diagnosis of acute appendicitis in women of reproductive age. Surg Endosc 2003;17:1311-1313.

20 Milewczyk M, Michalik M, Ciesielski M: A prospective, randomized, unicenter study comparing laparoscopic and open treatments of acute appendicitis. Surg Endosc 2003; 17:1023-1028.

21 Al-Mulhim AS, Al-Mulhim FM, Al-Suwaiygh AA, Al-Masaud NA: Laparoscopic versus open appendectomy in females with a clinical diagnosis of appendicitis. Saudi Med J 2002;23:1339-1342.

22 Little DC, Custer MD, May BH, Blalock SE, Cooney DR: Laparoscopic appendectomy: an unnecessary and expensive procedure in children? J Pediatr Surg 2002;37:310-317.

23 Huang MT, Wei PL, Wu CC, Lai IR, Chen RJ, Lee WJ: Needlescopic, laparoscopic, and open appendectomy: a comparative study. Surg Laparosc Endosc Percutan Tech 2001; 11:306-312.

24 Lavonius MI, Liesjarvi S, Ovaska J, Pajulo O, Ristkari S, Alanen M: Laparoscopic versus open appendectomy in children: a prospective randomised study. Eur J Pediatr Surg 2001;11:235-238. 
25 Lintula H, Kokki H, Vanamo K: Single-blind randomized clinical trial of laparoscopic versus open appendicectomy in children. $\mathrm{Br}$ J Surg 2001;88:510-514.

-26 Larsson PG, Henriksson G, Olsson M, et al: Laparoscopy reduces unnecessary appendicectomies and improves diagnosis in fertile women: a randomized study. Surg Endosc 2001;15:200-202.

27 Long KH, Bannon MP, Zietlow SP, et al: A prospective randomized comparison of laparoscopic appendectomy with open appendectomy: clinical and economic analyses. Surgery 2001;129:390-400.

28 Pedersen AG, Petersen OB, Wara P, Ronning $\mathrm{H}$, Qvist N, Laurberg S: Randomized clinical trial of laparoscopic versus open appendicectomy. Br J Surg 2001;88:200-205.

-29 Nordentoft T, Bringstrup FA, Bremmelgaard A, Stage JG: Effect of laparoscopy on bacteremia in acute appendicitis: a randomized controlled study. Surg Laparosc Endosc Percutan Tech 2000;10:302-304.

-30 Ozmen MM, Zulfikaroglu B, Tanik A, Kale IT: Laparoscopic versus open appendectomy: prospective randomized trial. Surg Laparosc Endosc Percutan Tech 1999;9:187189.

- 31 Perner A, Bugge K, Lyng KM, Schulze S, Kristensen PA, Bendtsen A: Changes in plasma potassium concentration during carbon dioxide pneumoperitoneum. Br J Anaesth 1999;82:137-139.

- 32 Hellberg A, Rudberg C, Kullman E, et al: Prospective randomized multicentre study of laparoscopic versus open appendicectomy. Br J Surg 1999;86:48-53.

- 33 Heikkinen TJ, Haukipuro K, Hulkko A: Cost-effective appendectomy. Open or laparoscopic? A prospective randomized study. Surg Endosc 1998;12:1204-1208.

34 Klingler A, Henle KP, Beller S, et al: Laparoscopic appendectomy does not change the incidence of postoperative infectious complications. Am J Surg 1998;175:232-235.

- 35 Macarulla E, Vallet J, Abad JM, Hussein H, Fernandez E, Nieto B: Laparoscopic versus open appendectomy: a prospective randomized trial. Surg Laparosc Endosc 1997;7:335339.

-36 Minne L, Varner D, Burnell A, Ratzer E, Clark J, Haun W: Laparoscopic vs. open appendectomy: prospective randomized study of outcomes. Arch Surg 1997;132:708-711; discussion 712 .

- 37 Reiertsen O, Larsen S, Trondsen E, Edwin B, Faerden AE, Rosseland AR: Randomized controlled trial with sequential design of laparoscopic versus conventional appendicectomy. Br J Surg 1997;84:842-847.
38 Kazemier G, de Zeeuw GR, Lange JF, Hop WC, Bonjer HJ: Laparoscopic vs open appendectomy: a randomized clinical trial. Surg Endosc 1997;11:336-340.

39 Laine S, Rantala A, Gullichsen R, Ovaska J: Laparoscopic appendectomy - is it worthwhile? A prospective, randomized study in young women. Surg Endosc 1997;11:95-97.

40 Hart R, Rajgopal C, Plewes A, et al: Laparoscopic versus open appendectomy: a prospective randomized trial of 81 patients. Can J Surg 1996;39:457-462.

41 Mutter D, Vix M, Bui A, et al: Laparoscopy not recommended for routine appendectomy in men: results of a prospective randomized study. Surgery 1996;120:71-74.

42 Williams MD, Collins JN, Wright TF, Fenoglio ME: Laparoscopic versus open appendectomy. South Med J 1996;89:668-674.

43 Lejus C, Delile L, Plattner V, et al: Randomized, single-blinded trial of laparoscopic versus open appendectomy in children: effects on postoperative analgesia. Anesthesiology 1996;84:801-806.

44 Cox MR, McCall JL, Toouli J, et al: Prospective randomized comparison of open versus laparoscopic appendectomy in men. World J Surg 1996;20:263-266.

45 Hansen JB, Smithers BM, Schache D, Wall DR, Miller BJ, Menzies BL: Laparoscopic versus open appendectomy: prospective randomized trial. World J Surg 1996;20:17-20; discussion 21.

46 Martin LC, Puente I, Sosa JL, et al: Open versus laparoscopic appendectomy. A prospective randomized comparison. Ann Surg 1995;222:256-261; discussion 261-262.

-47 Ortega AE, Hunter JG, Peters JH, Swanstrom LL, Schirmer B: A prospective, randomized comparison of laparoscopic appendectomy with open appendectomy. Laparoscopic Appendectomy Study Group. Am J Surg 1995; 169:208-212; discussion 212-213.

48 Lujan Mompean J, Robles Campos R, Parrilla Paricio P, Soria Aledo V, Garcia Ayllon J: Laparoscopic versus open appendicectomy: a prospective assessment. Br J Surg 1994; 81:133-135.

49 Frazee RC, Roberts JW, Symmonds RE, et al: A prospective randomized trial comparing open versus laparoscopic appendectomy. Ann Surg 1994;219:725-728; discussion 728-731.

50 Kum CK, Ngoi SS, Goh PM, Tekant Y, Isaac JR: Randomized controlled trial comparing laparoscopic and open appendicectomy. $\mathrm{Br} J$ Surg 1993;80:1599-1600.

-51 Tate JJ, Dawson JW, Chung SC, Lau WY, Li AK: Laparoscopic versus open appendicectomy: prospective randomised trial. Lancet 1993;342:633-637.

- 52 Attwood SE, Hill AD, Murphy PG, Thornton J, Stephens RB: A prospective randomized trial of laparoscopic versus open appendectomy. Surgery 1992;112:497-501.
53 Jadad AR, Moore RA, Carroll D, et al: Assessing the quality of reports of randomized clinical trials: is blinding necessary? Control Clin Trials 1996;17:1-12.

54 Sauerland S, Lefering R, Neugebauer EA: Laparoscopic versus open surgery for suspected appendicitis. Cochrane Database Syst Rev 2004;CD001546.

- 55 Diener MK, Blumle A, Szakallas V, Antes G, Seiler CM: Randomized and nonrandomized controlled clinical trials in a German surgical journal. Chirurg 2006;77:837-843.

56 Schulz KF, Grimes DA: Generation of allocation sequences in randomised trials: chance, not choice. Lancet 2002;359:515-519.

- 57 Altman DG, Doré CJ: Randomisation and baseline comparisons in clinical trials. Lancet 1990;335:149-153.

- 58 Schulz KF, Grimes DA: Allocation concealment in randomised trials: defending against deciphering. Lancet 2002;359:614-618.

- 59 Schulz KF, Chalmers I, Hayes RJ, Altman DG: Empirical evidence of bias: dimensions of methodological quality associated with estimates of treatment effects in controlled trials. JAMA 1995;273:408-412.

60 Paradis C: Bias in surgical research. Ann Surg 2008;248:180-188.

61 Juni P, Altman DG, Egger M: Systematic reviews in health care: assessing the quality of controlled clinical trials. BMJ 2001;323:4246.

62 Macklin R: The ethical problems with sham surgery in clinical research. N Engl J Med 1999;341:992-996.

63 Horng S, Miller FG: Is placebo surgery unethical? N Engl J Med 2002;347:137-139.

64 Schulz KF, Grimes DA: Sample size calculations in randomised trials: mandatory and mystical. Lancet 2005;365:1348-1353.

65 Halpern SD, Karlawish JH, Berlin JA: The continuing unethical conduct of underpowered clinical trials. JAMA 2002;288:358362 .

66 Fergusson D, Aaron SD, Guyatt G, Hebert P: Post-randomisation exclusions: the intention to treat principle and excluding patients from analysis. BMJ 2002;325:652-654.

67 Moher D, Schulz KF, Altman D: The CONSORT statement: revised recommendations for improving the quality of reports of parallel-group randomized trials. JAMA 2001; 285:1987-1991.

68 Chan AW, Hrobjartsson A, Haahr MT, Gotzsche PC, Altman DG: Empirical evidence for selective reporting of outcomes in randomized trials: comparison of protocols to published articles. JAMA 2004;291:24572465. 